\title{
The University Professor: The Attributes \& Characteristics as Seen by the Hashemite University Students
}

\author{
Zohair H. Al-Zoubi ${ }^{1} \&$ Ahmad M. Mahasneh ${ }^{2}$ \\ ${ }^{1}$ Department of Curricula and Instruction, Faculty of Educational Science, Hashemite University, Jordan \\ ${ }^{2}$ Department of Educational Psychology, Faculty of Educational Science, Hashemite University, Jordan \\ Correspondence: Ahmad M. Mahasneh, Department of Educational Psychology, Faculty of Educational Science, \\ Hashemite University, Zarqa, Jordan. E-mail: dahmadmahasneh1975@yahoo.com
}

\author{
Received: May 30, 2013 Accepted: July 12, 2013 Online Published: September 29, 2013 \\ doi:10.5539/ass.v9n13p1 URL: http://dx.doi.org/10.5539/ass.v9n13p1
}

\begin{abstract}
The study aimed knowing the qualities and characteristics of a university professor in the light of contemporary global changes as views by the Hashemite University students, and their views differences regarding to their sex, college, academic level, and GPA. The study sample consisted of (1148) students registered for the second semester 2010/2011.

Results indicate that the qualities and characteristics of a university professor views by the Hashemite University students in high degree on the total, and ranked the dimensions of the study, respectively: personal, professional and scientific, and social dimension. Also results of the study showed there were statistically significant differences in the views of students regarding to their sex (favor for female), with regard to college (favor for scientific), regarding to the academic level (favor for first and second year), and with regard to GPA (favor for students with an excellent and very good GPA).
\end{abstract}

Keywords: Hashemite University, university professor, university students

\section{Introduction}

The role of universities has grown in different communities, and the number of universities has increased. As a result, the number of students and professors has increased, and the roles the universities are assuming towards societies have varied. The university professor is considered the foundation stone within the university structure as the status and reputation of any university are closely related to its academic level and the professor's position who work for it. Thus, remarkable universities in the developed and civilized countries take care of enabling and orienting their professors on all levels, and choose them according to their academic standard, competence, curriculum vitae and personality tests that are conducted in accordance with particular measures.

It is taken for granted that the university professor's mission doesn't only entail providing students with the correct knowledge, but it does beyond that. Regardless of his/her specialty whether scientific or humane, the university professor is basically an educationalist, so he/she has to understand the social principles of education so as to contribute effectively to the process of guiding and directing students. That means his/her mission is educational, trying to impart the cultural side to his/her students in order to affect their behavior and thought as well as helping them discover their selves, and change their attitudes, beliefs, values and habits. Besides, he/she must have the ability of conducting scientific research within his/her specialty. He/she must be able to renew his/her lectures and knowledge, plus the technical and scientific capability to act properly. He/she should follow and cope with the procession of scientific advance, and be a good model that could be imitated by the students. Being like that, the professor would affect the student's and the individual's behavior and character. In addition, the competent professor should have the qualities of successful leadership techniques, and he/she is supposed to lead the students towards achieving the educational goals, and creating the spirit of cooperation and agreement with others (Al-Sahlawi, 1992).

The career of university teaching is considered very essential as it is the main job in many remarkable universities in the world. It mainly focuses on preparing students in a way that enable them to encounter present and future challenges with all of their technological and scientific developments (Ali, 1987). 
The career of university teaching is considered one of the most important jobs at universities and the most effective in preparing students for future life. It provides them with major knowledge, positive ethical and behavioral attitudes and all the practical and scientific skills needed to orient them to become efficient members in their societies. The criterion of measuring the university's success depends mainly upon the well-qualified professors it has where it provides them with the suitable circumstances and facilities such as the proper academic atmosphere as well as other services that contribute to improving the teaching process to be able to meet the needs of the comprehensive advancement process and the increasing requirements of this generation (frohwald, 2003).

The university professor should own the proper qualities that Ernest Hilgard considers as basic foundations for the normal character, and the most important ones are the effective and respectful realization of reality, the knowledge and acceptance of self regarding needs, feelings and motives as well as the ability of creating sound social relationships. The university professor should also own the leadership skills, and should be characterized with mental, social and emotional attributes and features that characterize the successful educational leader. The mental features can be briefed into intelligence, scientific competence, widened horizon, comprehensive knowledge and culture, insight, good manners, creative thinking, wise decision making, and the ability of influencing and convincing. On the other hand, the emotional qualities are love, affection, passionate stability, sentimental sharing, self-confidence, willpower, and self-control. Some of the most important social features for successful leadership are cheerfulness, spirit of humor, merriment, democracy, spirit of cooperation, bearing responsibility, leniency, acceptance of criticism and respecting other's opinions (Ibrahim, 2000).

It is noticed that the efficiency of university education is determined by the efficiency of the professor, his/her proficiency in creating the suitable learning atmosphere and developing the students' mental motivation, the positive communication between them, and the nature of the connections that could help in motivating students to do their best and exert their efforts for perfect scientific achievement. In turn, that would affect their standard and the degree of their positive interaction (Al-Khatheila, 2000).

The styles of university professors have varied as well as their preparation sources since they are distinguished and considered the top in their intellectuality. But they may not have the suitable instructional competencies so as to deliver their knowledge to their students. Thus, many students may complain about the discourteous relations or interrupted communication between them and their professors. Professors who are affectionate and warmhearted towards their students enjoy their love and the respect, and that affects students' love of their studying (Woolfolk, 1998).

It is significant that university professors should have instructional competencies. Studies unanimously agreed on the existence of a backward relation between students' rejection of the professor and their academic achievement. Students who are highly acceptable to their professors are the ones who have a higher achievement than other students. Studies found that experienced professors are able to deal with complicated situations at the lecture room. They are also capable of making and taking proper decisions related to the learning process, as well as dealing with the content through setting main ideas that are understandable and meaningful (Kauchak \& Eggen, 1998).

There is no doubt that this era witness's knowledge upheaval, informational flow, revolution in communication means and informational technology, and variation in teaching methods. So, the university professor our generation needs is a person who enjoys high quality capabilities, qualifications and attributes in order to fit the astonishing developments the world witnesses within the field of scientific research and higher education. At the same time, the old tools and methods are no longer able to meet the requirements of this era and the needs of the new generations and societies. Thus, the university professor we seek is the teacher, the researcher, the educator, and the effective member in his/her society and for the whole humane society. He/she should also be armed with old and modern culture, and some active global languages. He/she ought to have a close relationship with communication technology as well as being familiar with the teaching methods, following eagerly the recent developments and renewals within his/her specialization. Searching for Excellency in the academic performance needs familiarity with points of strength and weaknesses for each of the performance elements, and reinforcement of the strength factors and correction of the weaknesses (Al-Tartouri \& Jweihan, 2006).

The new professional responsibilities for any professor in the $21^{\text {st }}$ century revolve around a core notion which is that the university teacher should be transferred into a constant learner who performs his job reasonably and reflectively, and progresses professionally to improve his/her performance. Doing so, he/she will be changed into a leader and advisor for the students, conducting scientific research, and collaborating with others to produce knowledge and solve the society's problems as well as the continuous updating through studying and inspection 
(Al-Harahsheh \& Al-Noubani, 2008).

\section{Previous Studies}

Al-Aghbari (1996) reached the result that the most essential 10 qualities for the university professor are: ability to link the content to reality, familiarity with the content, commitment to Islamic values, ability to deliver information, good-looking appearance, scientific spirit for research and publication, modesty, being patient, ability to keep discipline and being proud of the position.

Abdullah's study (1997) revealed that there is a specific arrangement for the good professor characteristics as realized by the students, and they are: the social qualities like sympathy, kindness, love for students, leadership, flexibility in treatment, being a good model, modesty, classroom interaction and good-looking appearance, the personal qualities such as patience, intelligence, self-confidence, emotional poise, specialized scientific knowledge, linguistic competence and the good teaching method, and the professional qualities such as the alive professional conscience, respecting students, objective dealing with students, fairness in assessment, motivation and being committed to appointments.

Al-Najji (1998) came up with the idea that professors and students agree on the most important features professors should have, and that would lead to increasing the students' academic achievement. They are: using different teaching and assessment tools, being acquainted with the content, the positive interaction with the students, as well as exerting more efforts in delivering lectures. On the other hand, university teachers see that the most important features are charging students with homework and evaluating them, and being accurate in lecture timing and office hours. Whereas students see that concern for students' problems, providing them with help and support, having an attractive personality that possesses love, fairness and amplitude, and considering individual differences are the most important features.

Ja'niny (2000) stated that the competence of being committed to the job morals is the needed attribute according to the competencies' order, followed by the instructional skills and classroom management, then the skill of planning, and then the cognitive competencies, then comes assessment and judging, and finally comes the skills of communication.

Al-Ghamidi (2003) mentioned that the most common preferable academic features for the university teacher were the following: the ability to deliver the content to students, the good preparation for the lectures, the familiarity with the content and following the updated material, whereas the most common ethical features were: the rigorous commitment to the morals of the teaching process, the respect for the lesson times, and the good treatment for students. Besides, the personal characteristics were: keeping the secrets of students' personal information, adherence to ethics, allegiance to work, and being a good model. In addition, the most common social features within this study were: adherence to the society's culture and its Islamic identity, the good relationship with colleagues, and recognizing the importance of education in building the society.

Jacob's study (2005) came up with the findings which stated that the most important professional competencies are: being well-informed about science and knowledge within numerous fields, being well-acquainted with content and its teaching methods, and the ability to link content to real life. Whereas the competencies within the personal dimension are: the importance of clear audible voice, tidiness, good-looking appearance, cheerfulness, steady emotional responses, discipline, firm decisions, and commitment to current values and traditions.

Abu Awwad (2008) said that there were no statistically significant differences for the distinguished professor's characteristics ascribed to the variables of gender, scientific qualification and years of experience. Whereas, there were significant differences ascribed to specialization for the benefit of teachers whose major is teaching the first three basic classes.

Mahafzeh (2009) has come up with the most important features for the future professor, and they were: good knowledge of the content, investigating the learners' features, abilities and characters, good skill of teaching and assessment methods, ability to interact with students, willingness for sustainable professional development, and ability to use computers and other different teaching technologies. Besides, the study revealed the essential competencies needed for professors which were: the theoretical and scientific preparation for professors, commitment to the career's ethical principles, willingness for community service and connection, and the ability to conduct scientific research. Besides, the necessary procedures for improving the quality of professors are: enabling professors and establishing good criteria for teachers' selection.

Clinton (1980) reached the result that the characteristics that occupied the first rank were the ones that refer to the social, ethical and personal aspects like caring for students, honesty, clarity, and cheerfulness. On the other hand, the qualities that took the last rank were the ones that are connected to academic and scientific aspects like 
the ability to control the content and deliver it clearly to students.

Hoag, et al., (1988) mentioned the most important factors that affect the professor's reputation. They were the features of friendship and warmth, interest for students, respecting their views, good-looking appearance, and the attractive character. He also stated that these were also the basic reasons why students like to register courses at university with professors who have these features.

Ott's study (1991) which aimed at identifying the instructional academic features for the university professor came up with the findings that clarified the increase in students' preference and interest in courses whose teachers' lectures are more thrilling and are characterized with ample acquaintance of the content, ability to convey it skillfully, and the ability to relate it to students' real life situations.

Roney (2000) conducted a study that aimed at identifying the characteristics of effective middle-stage teachers from the point of view of principles, teachers and students (a case study), in which the interview method was utilized with (32) participants. The results revealed the most common features which were: flexibility, adaptation, kindness, enthusiasm, classroom management, skills of communication, patience, honesty and creativity.

Haskvitz (2007) pointed out in an article entitled "Eleven Qualities for the Good Teacher" that there are shared features between distinguished professors such as the wide acquaintance and knowledge, persistence on learning and searching for the new, establishing rules for dealing with students, realizing what they need now and in future, as well as expecting the highest from them that motivates them to do their best, and consequently be happy of what they achieve. Also, helping students to be independent and self-esteemed, the ability to communicate, the flexibility in dealing with them, simplifying the instructional material, kindness and cheerfulness, using exciting stories that attract students' attention, using various methods, introducing interesting activities that eliminate boredom, increase motivation and make students willing for learning, and finally introducing a quick and accurate assessment for their work.

\section{Statement of the Problem}

The $21^{\text {st }}$ century witnessed a scientific and technological revolution that exceeds imagination, and there is no doubt that education has led to that current revolution since it has produced scientists, engineers, technicians and researchers. Simultaneously, education has also been affected by this revolution as the interaction between education and technological development is strong in this decade. This relation has been translated into a modification in the curriculum and teaching materials. Technology has entered the educational institutions. Thus, the learner has found other untraditional resources for learning and depended on them. As a result, the traditional styles became unable to face the requirements of the development. Also, the variables and challenges that distinguish this decade became more effective on the instructional systems in general, and on the higher education in specific. The university professor is the effective part of the university instructional process, and its basic stimulant, since his/her cognitive and emotional qualities play an important role in the efficiency of the instructional process. Also because of the fact that whatever the level of the curriculum presented at the university as well as the facilities, structures and laboratories available there, the university can't achieve the targeted goals and impose its scientific and social leadership unless it has the competent professor who is characterized with some unique features. Based on that, the problem of the study is represented in answering the following questions:

RQ1: What are the qualities and features of the university professor as seen by the Hashemite University students?

RQ2: Do these features as seen by the Hashemite University students differ according to the variables of gender, college, the students' instructional level and his average?

\section{Impotence of the Study}

The success of the university instructional process is associated to many issues such as the student's willing and interest in learning, and the efforts the administration exerts in organizing and providing them with needs and facilities. Still, the professor's role remains the major in promoting the teaching process since teaching is his/her major duty at the university. His/her success in teaching means preparing students, and educating them in an integral way, spiritually, ethically, physically, and socially so as to be good citizens who are able to contribute to their society's progress. The importance of the study comes out through:

1) The importance of the university teacher and his/her active role in accomplishing the university's goals.

2) The importance of identifying the professor's qualities and attributes from the students' point of view, and its contribution to helping the professor and the university administration in identifying the strengths of the 
professors' characteristics so as to reinforce and encourage them as well as the weaknesses so as to handle and avoid them.

3) In light of the results and recommendations of this study, they can help the university administration in developing the professor's professional training program and setting standards for selecting them as well as the in-service training program for them.

\section{Method \& Procedures}

\subsection{Participants}

The population of this study consisted of (16398) undergraduate students, who were enrolled in the faculties of Hashemite University in the academic year 2011/2012, who represent all levels of study at (HU). For the purpose of this study, a random sample was chosen from the population, it consisted of (1148) and it represents a percentage of $7 \%$ of the study community.

\subsection{Instrument}

The researchers created the tool of the study after reviewing the available educational literature related to this field. They looked into many resources, researches and studies related to this field. They also examined the related standards such as Abdullah's study (1997), Ja'nini's study (2000), Al-Ghamidi's study (2003), Jacob's study (2005) and Abu Awwad's study (2008).

1) Based on the review of the educational and psychological literature and other previous studies, the dimensions of the study and were identified as well as the items in their initial version so as to fit the study's environment.

2) Some interviews were conducted with students, and the notes and suggestions were recorded regarding the professor's characteristics.

3) After preparing the first formula of the tool which consisted of (55) items distributed among the 3 dimensions, it was reviewed by a group of referees who were professors at the Yarmouk University and Jordan University, with a total of (12) persons in order to determine the items' and dimensions' suitability for achieving the goals of the study.

4) Later, some items were modified and some were deleted on the basis of the referees' views to come up with its final version of (47)items distributed among 3 dimensions:

a) The personal dimension which consists of (15) items.

b) The professional and academic dimension which consists of (19) items.

c) The social dimension which consists of (13) items.

The answers' scale has five alternatives for responses prepared using Lickert's scale.

The validity of the tool's content was verified when the researchers presented the tool to the group of arbitrators (professors of the Yarmouk \& Jordan University), and asked them to verify its linguistic validity, modify the content of the items (questions) and delete what they consider suitable. In light of the notes presented by the referees, the needed procedures were done and the total of the items became (9), where each items represents a question.

The stability of the tool was examined using the re-testing method, with a time difference of 2 weeks. That test was implemented on a group of (120) male and female students outside the study sample to determine the tool's stability. The total stability coefficient was $(0.82)$, and for the purpose of increasing the accuracy of the tool's stability, Chronbach Alpha's formula was used to calculate the stability. The calculated entire stability coefficient was (0.90), and it is considered significant and adequate for the purposes of this research. Table 1 clarifies this.

Table 1. Stability coefficient according to chronbach alpha's formula

\begin{tabular}{lll}
\hline No. of dimension & Dimension & Stability coefficient \\
\hline 1 & Personal & 0.90 \\
2 & Professional \& Academic & 0.88 \\
3 & Social & 0.92 \\
Total & & 0.90 \\
\hline
\end{tabular}




\subsection{Correcting Procedures for the Tool of the Study}

To modify the tool of the study, the students' opinions were divided into 3 levels: high (more than 3.5), medium (2.5-3.49), and low (less than 2.49).

\subsubsection{Steps of Applying the Study:}

1) Getting the permission from the Hashemite University administration for the application of the study upon the B.A. students.

2) Getting the timetable for the studying courses from the registration and admission department for the second semester of 2010/2011.

3) Recording the courses and sections numbers in lists, where each list represents a college either scientific or humanitarian. Then, numbers were selected randomly.

4) Distributing a questionnaire among the sample participants, and the total number of distributed questionnaires was (1250). (1165) were returned, and after investigating them, (17) questionnaires were found unfilled properly, so they were excluded from the sample. Eventually, the analyzable sample became (1148) questionnaires, representing approximately $7 \%$ of the study community.

5) Data was extracted so as to be processed statistically through computer.

6) Statistical processing was conducted using SPSS program for the analyzable questionnaires.

\subsubsection{Statistical Processing}

For the purpose of answering the study questions, the researchers used the following statistical processing: means, standard deviations, percentages, t-test, One-way ANOVA, and Shefe test to identify the differences between the means.

\section{Rustles and Discussion}

This part of the study includes a presentation of the results this study have reached and a discussion for them.

1) Question 1: what are the professors' qualities and features in light of the current global changes as seen by the Hashemite university students?

To answer this question, means and SDs were calculated for each dimension of the tool, and for each item for the 3 dimensions, in accordance to the dimension the item refers to. Next, results related to this question will be displayed for each dimension separately then for all of them as a whole. Tables $(3,4,5,6)$ show means and SDs for the participants' answers.

First: the personal dimension

Table 2 reveals the items of the personal dimension that are related to the professor's features and attributes, and it also shows the means and SDs for this dimension items.

Table 2. Means \& standard deviations for the participants' answers on the items of the personal dimension

\begin{tabular}{lllll}
\hline Item content & rank & mean & SD & degree \\
\hline Attains equity between students & 1 & 4.73 & 0.45 & high \\
Appears in a good-looking appearance in front of students. & 3 & 4.66 & 0.60 & high \\
Be humble and accepts criticism. & 9 & 3.78 & 0.54 & high \\
Self-confident, objective and strict. & 5 & 4.57 & 0.68 & high \\
Be healthy and able to work actively. & 10 & 3.76 & 0.61 & high \\
Be precise in time, arrives before students and leaves after them. & 8 & 3.87 & 0.43 & high \\
Has good morals and treats students properly. & 11 & 3.73 & 0.40 & high \\
Escorts global updates specially in his/her specialty. & 2 & 4.67 & 0.67 & high \\
Be intellectual, open-minded and interested in culture generally. & 15 & 3.26 & 0.80 & medium \\
Be loyal and lover to the career, conserving its reputation. & 13 & 3.60 & 0.71 & high \\
Possesses linguistic capacity and speech eloquence. & 4 & 4.65 & 0.68 & high \\
Possesses the values of work and discipline. & 6 & 4.56 & 0.80 & high \\
Believes in God, nation and profession. & 7 & 4.51 & 0.82 & high \\
Be calm, patient, ambitious and optimistic. & 12 & 3.70 & 0.58 & high \\
Enjoys sufficient physical energy & 14 & 3.48 & 0.81 & medium \\
The entire average for the dimension & & 4.16 & 0.55 & high \\
\hline
\end{tabular}


Results displayed in Table 2 show that the answers of the students on the personal dimension items have had high degrees as they got means that ranged from (4.73) as the highest point and (3.26) as the lowest. The item of (attains equity between students) got the first rank for an average of (4.73), then comes the item of (escorts global updates specially in his/her specialty.) in the second place for an average of (4.67). The third rank was given to the item of (appears in a good-looking appearance in front of students) that has an average of (4.66).

That could be explained according to what students are offered before going to university, and the technological revolution output including the global changes that affect their view of the university educator. They see him/her the fair, just and educated person who follows the global changes in different aspects specially his/her specialty. $\mathrm{He} / \mathrm{she}$ is also seen as a model imitated in the style of dressing and appearance because that indicates the type of personality. Moreover, he/she is the students' model regarding the character and behavior.

That what most studies pointed out regarding the most important features for university professors like Clinton's study (1980), Ott's study (1991), Hoag \& others' study (1988), Al-Aghbari's study (1996), Abdullah's study (1997), Roney's study (2000), Al-Ghamidi's study (2003), Jacob's study (2005), Diab's study (2006), Haskvitz's study (2007), Abu Awwad's study (2008) and Mahafzeh's study (2009).

Second: the professional \& academic dimension

Table 3 shows the items of this dimension that are related to the professor's qualities and attributes, and it also displays the means and SDs for the items of this dimension.

Table 3. Means \& standard deviations for the participants' answers on the items of the professional \& academic dimension

\begin{tabular}{|c|c|c|c|c|}
\hline Item content & rank & mean & SD & degree \\
\hline Going deeply into the specialty field. & 1 & 4.75 & 0.45 & high \\
\hline Motivating students towards learning. & 14 & 3.80 & 0.39 & high \\
\hline $\begin{array}{l}\text { Encouraging students' talents and teaches them how to develop their } \\
\text { creative abilities. }\end{array}$ & 6 & 4.44 & 0.83 & high \\
\hline Continual acquaintance with the updates. & 18 & 3.26 & 0.80 & medium \\
\hline Keeping discipline inside the classroom. & 10 & 4.26 & 0.68 & high \\
\hline Training students on acquiring necessary skills for positive thinking. & 19 & 3.01 & 0.76 & medium \\
\hline Ability to diagnose difficulties students face and solving them & 13 & 3.85 & 0.74 & high \\
\hline Following tasks and duties and considering them in assessment. & 3 & 4.60 & 0.48 & high \\
\hline Reading a lot especially about global updates related to his/her field. & 2 & 4.70 & 0.65 & high \\
\hline Leading a democratic lectures' atmosphere. & 4 & 4.47 & 0.74 & high \\
\hline $\begin{array}{l}\text { Identifying the lectures' goals and relates them to the recent generation } \\
\text { developments. }\end{array}$ & 8 & 4.38 & 0.84 & high \\
\hline Tracking the scientific updates and innovations. & 5 & 4.45 & 0.82 & high \\
\hline Progressing from the known to the unknown in lectures. & 16 & 3.72 & 0.39 & high \\
\hline Ability to stimulate students and instills love for learning. & 17 & 3.54 & 0.80 & high \\
\hline $\begin{array}{l}\text { Likes his/her material and improves it according to the recent global } \\
\text { updates. }\end{array}$ & 9 & 4.35 & 0.53 & high \\
\hline Considers the individual differences between students. & 7 & 4.40 & 0.79 & high \\
\hline Ability for linking and sequencing ideas and logically. & 11 & 4.20 & 0.66 & high \\
\hline Correcting papers accurately and objectively. & 5 & 3.79 & 0.57 & high \\
\hline Being a developed and renewing teaching reference. & 12 & 3.90 & 0.61 & high \\
\hline The entire average for the dimension & & 4.04 & 0.49 & high \\
\hline
\end{tabular}


We can notice through the results displayed in Table 3 that the students' answers on the items of this dimension showed high degrees as they got averages that ranged from (4.75) as the ultimate to (3.01) as the lowest. The item of (going deeply into the specialty field) occupied the first rank for an average of (3.75), and then came the item of (reading a lot especially about global updates related to his/her field.) in the second rank for an average of (4.70). Thirdly came the item of (following tasks and duties and considering them in assessment.) that had an average of (4.60).

These results can be explained due to the students' use of the Internet and following the programs of the huge satellite channels. That has affected the students' knowledge and culture about his/her specialty, which consequently reflects upon his/her impression about the university educator. As a result, this educator needs an urgent increase in knowledge and a thorough study of his specialization since the current generation of students have got a preliminary knowledge on everything. So, the educator needs to be the professional and academic model for students who follows the updates and who is proficient in various methods and styles.

That what most studies have come up with around the necessity of the professors' acquaintance with any thing related to his/her specialization as a basic feature that characterized the university teacher, such as Clinton's study (1980), Ott's study (1991), Hoag \& others' study (1988), Al-Aghbari's study (1996), Abdullah's study (1997), Roney's study (2000), Al-Ghamidi's study (2003), Jacob's study (2005), Diab's study (2006), Haskvitz's study (2007), Abu Awwad's study (2008) and Mahafzeh's study (2009).

Third: the social dimension

Table 4 shows the items of this dimension that are related to the professor's qualities and attributes, and it also displays the means and SDs for the items of this dimension.

Table 4. Means \& standard deviations for the participants' answers on the items of the social dimension

\begin{tabular}{|c|c|c|c|c|}
\hline Item content & rank & mean & SD & degree \\
\hline $\begin{array}{l}\text { Has the ability to make his meeting with students similar to one-family } \\
\text { gathering. }\end{array}$ & 4 & 3.97 & 0.49 & high \\
\hline $\begin{array}{l}\text { Transfers his experiments and experiences to students through } \\
\text { instructional situations. }\end{array}$ & 7 & 3.89 & 0.47 & high \\
\hline Enjoys a distinguished economical and social status. & 12 & 3.72 & 0.35 & high \\
\hline Has a successful relation with colleagues, employers and students. & 3 & 4.00 & 0.49 & high \\
\hline Being humble, cooperative, and respectful for other's feelings. & 1 & 4.11 & 0.51 & high \\
\hline Being aware of students' features, needs and abilities. & 2 & 4.05 & 0.59 & high \\
\hline Being a social conciliator who has a specific role in solving disputes. & 13 & 3.71 & 0.35 & high \\
\hline $\begin{array}{l}\text { Handles students' educational, social, emotional and psychological } \\
\text { problems. }\end{array}$ & 5 & 3.95 & 0.49 & high \\
\hline Takes part in social occasions. & 9 & 3.80 & 0.41 & high \\
\hline Being patient towards students' mistakes and treat them gently. & 10 & 3.78 & 0.49 & high \\
\hline $\begin{array}{l}\text { Being interactive and cooperative with colleagues in local community } \\
\text { services. }\end{array}$ & 11 & 3.77 & 0.43 & high \\
\hline $\begin{array}{l}\text { Appreciates the values of justice, and believes in the principle of equality } \\
\text { of opportunities and develops it. }\end{array}$ & 8 & 3.84 & 0.45 & high \\
\hline $\begin{array}{l}\text { Have the skills of communication and building good relations with } \\
\text { others. }\end{array}$ & 6 & 3.94 & 0.49 & high \\
\hline The entire average for the dimension & & 4.02 & 0.57 & high \\
\hline
\end{tabular}

We can notice through the results displayed in Table 4 that the students' answers on the items of this dimension showed high degrees as they got averages that ranged from (4.11) as the ultimate to (3.71) as the lowest. The item of (being humble, cooperative, and respectful for other's feelings) occupied the first rank for an average of (4.11), then came the item of (being aware of students' features, needs \& abilities.) in the second rank for an 
average of (4.05). Thirdly came the item of (has a successful relation with colleagues, employers \& students.) that had an average of (3.71).

The reason behind this result is that the social aspects form a base within our life, and while bringing up our kids we focus on this side like clinging to Islamic values and respecting habits and traditions and the society values. Thus, students appeared more interested in the items of this dimension. Consequently, students see that the social characteristics the professor should have must be consistent with the good social features and original values they were taught. According to society, the university professor represents the social model as he is the one who got the highest scientific degrees and works for the highest educational institution. He is also the one who is able to change students' route, provides them with knowledge and teaches them the basics of science and religion. Thus, he is the model for society, and that result in the students' impression about the professor that he is their social model in everything.

Most studies assured the importance of the social side as an essential feature for the professor such as Clinton's study (1980), Ott's study (1991), Hoag \& others' study (1988), Al-Aghbari's study (1996), Abdullah's study (1997), Roney's study (2000), Al-Ghamidi's study (2003), Jacob's study (2005), Diab's study (2006), Haskvitz's study (2007), Abu Awwad's study (2008) and Mahafzeh's study (2009).

Regarding the comparison between means and standard deviations for the Hashemite University students' views about the professor's characteristics within the 3 dimensions and the performance as a whole, Table 5 displays the order of the dimensions in accordance to their means.

Table 5. Means \& SDs for the 3 dimensions and for the whole performance

\begin{tabular}{lllll}
\hline No. & dimension & No. of items & mean & SD \\
\hline 1 & Personal & 15 & 4.16 & 0.55 \\
2 & Professional \& academic & 19 & 4.04 & 0.49 \\
3 & Social & 13 & 3.88 & 0.51 \\
The total average for dimensions & $\mathbf{4 7}$ & $\mathbf{4 . 0 2}$ & $\mathbf{0 . 5 7}$ \\
\hline
\end{tabular}

Results displayed in Table 5 indicated that all dimensions demonstrated a high degree based on the participants' answers, as well as the entire degree for the dimensions. The personal dimension got the first rank for an average of (4.16) and a standard deviation of (0.55), whereas the professional/academic dimension achieved the second place with an average of (4.04), and an SD of (0.49), and lastly came the social dimension for an average of (3.88), and an SD of (0.51). On the other hand, the total average for the 3 dimensions reached a high degree with an average of (4.02), and an SD of (0.57).

Based on what has been mentioned and through the results displayed in Table 6, all the means for the study dimensions got a high degree as they ranged from (4.16) to (3.88), and also the total mean which was (4.02) with a high degree as well.

Researchers ascribe that to the university students' high vision of their professors' characteristics as they see those models within the different dimensions, personal, social, professional and academic.

2) Question 2: Do Hashemite University students' opinions about their professors' characteristics differ in light of the recent global variables and according to gender, college, studying level or stage and the students' average?

First: according to the variable of gender

To answer this question, means, standard deviations and t-test were calculated, and Table 6 shows these calculations for the students' opinions about their professors' features according to gender. 
Table 6. Means \& SDs \& t-test according to gender

\begin{tabular}{|c|c|c|c|c|c|c|c|c|c|}
\hline \multirow{2}{*}{ No. } & \multirow{2}{*}{ Dimension } & & \multicolumn{2}{|l|}{ males } & \multicolumn{2}{|c|}{ females } & \multirow{2}{*}{ t-value } & \multirow{2}{*}{$\begin{array}{l}\text { Significance } \\
\text { level }\end{array}$} & \multirow{2}{*}{ Significance } \\
\hline & & & mean & SD & mean & SD & & & \\
\hline 1 & Personal & & 3.50 & 1.72 & 3.57 & 1.06 & 0.250 & 0.041 & significant \\
\hline 2 & $\begin{array}{l}\text { Professional } \\
\text { Academic }\end{array}$ & $\&$ & 3.36 & 1.12 & 3.43 & 1.23 & 0.226 & 0.022 & significant \\
\hline 3 & Social & & 3.14 & 1.19 & 3.61 & 1.17 & 1.46 & 0.043 & significant \\
\hline Total & & & 3.15 & 0.70 & 3.42 & 0.83 & 1.37 & 0.017 & significant \\
\hline
\end{tabular}

Results mentioned in Table 6 indicate the existence of statistically significant differences between the male and female students within the 3 dimensions and the entire average for the dimensions, and for the benefit of females.

This result can be explained that female students have more interest than male students in talking about the professors' characteristics since females in our societies have an interest in criticizing the features of the university professor. They have the social and cognitive plunge, and during this age they address the issues of dream knight and social model, unlike male students whose interest is in building friendships with their colleagues as well as thinking about life after graduation and future. Therefore, the differences regarding the features of the university professor were for the benefit of female students.

Second: according to the variable of college

To answer this question, means, standard deviations and t-test were calculated, and Table 7 shows these calculations for the students' opinions about their professors' features according to college.

Table 7. Means \& SDs \& t-test according to college

\begin{tabular}{|c|c|c|c|c|c|c|c|c|c|}
\hline \multirow{2}{*}{ No. } & \multirow{2}{*}{ Dimension } & & \multicolumn{2}{|c|}{ scientific } & \multicolumn{2}{|c|}{ humanitarian } & \multirow{2}{*}{ t-value } & \multirow{2}{*}{$\begin{array}{l}\text { Significance } \\
\text { level }\end{array}$} & \multirow{2}{*}{ Significance } \\
\hline & & & mean & SD & mean & SD & & & \\
\hline 1 & Personal & & 3.70 & 1.41 & 3.32 & 1.38 & 1.81 & & significant \\
\hline 2 & $\begin{array}{l}\text { Professional } \\
\text { Academic }\end{array}$ & $\&$ & 3.82 & 1.12 & 3.39 & 1.22 & 1.36 & & significant \\
\hline 3 & Social & & 3.89 & 1.34 & 3.75 & 1.32 & 0.80 & & significant \\
\hline Total & & & 3.42 & 0.70 & 3.13 & 0.83 & 1.37 & ${ }^{*} 0.1$ & significant \\
\hline
\end{tabular}

Results mentioned in Table 7 indicate the existence of statistically significant differences between the scientific colleges students and humanitarian colleges students within the 3 dimensions and the entire average for the dimensions, and for the benefit of scientific colleges students.

This result can be explained that the scientific college's students care for the content presented to them by their professors, focusing on the updated information related to their major field, and they are connected to their professors both scientifically and cognitively. Therefore, they consider them as models in everything because of their basic scientific interest. They don't waste their time because of the difficulty of their specialization and the huge amount of assignments and laboratories. According to them, the professor's character is associated with the knowledge he presents to them. Thus, professors are their model within the personal, academic, professional and social domains.

Third: according to the variable of student's studying level/stage

To reveal the significance of differences according to the variable of student's studying level, means, and One-way ANOVA were calculated to see if there were statistically significant differences for the Hashemite University students' opinion about the university professors' features. Table 8 shows these calculations according to the variable of student's studying level. 
Table 8. Means \& SDs \& one-way anova according to student's studying level

\begin{tabular}{llllll}
\hline Variable & & No. & mean & f-value & Significance level \\
\hline \multirow{3}{*}{ Student's } & $1^{\text {st }}$ year & 344 & 3.86 & & \\
studying level & $2^{\text {nd }}$ year & 287 & 3.75 & \multirow{2}{*}{1.78} & 0.044 \\
& $3^{\text {rd }}$ year & 274 & 3.59 & & \\
& $4^{\text {th }}$ year & 253 & 3.62 & & \\
\hline
\end{tabular}

It is clear from Table 8 that there are statistically significant differences for the Hashemite University students' opinions according to the variable of students' university level/stage. To reveal the positions of these significant differences between the means of the students' opinions according to these variable, researchers used Shefe test for post comparisons so as to discover the source of differences, and Table 10 clarifies that.

Table 9. Shefe test for identifying the source of difference according to the variable of student's studying level/stage

\begin{tabular}{|c|c|c|c|c|c|c|}
\hline Variable & & mean & $1^{\text {st }}$ & $2^{\text {nd }}$ & $3^{\text {rd }}$ & $4^{\text {th }}$ \\
\hline \multirow{4}{*}{$\begin{array}{l}\text { Student's studying } \\
\text { level }\end{array}$} & $1^{\text {st }}$ year & 3.86 & & * & $*$ & * \\
\hline & $2^{\text {nd }}$ year & 3.75 & & & $*$ & $*$ \\
\hline & $3^{\text {rd }}$ year & 3.59 & & & & \\
\hline & $4^{\text {th }}$ year & 3.62 & & & & \\
\hline
\end{tabular}

As seen in Table 9, there are statistically significant differences for the students' opinions about their professors' characteristics according to the variable of studying level, and for the benefit of $1^{\text {st }}$-year students then $2^{\text {nd }}-$ year students.

This result could be explained that the first and second year students have model implications regarding the teachers' features in accordance to the society's visions. They are still affected by their families' and societies' visions regarding the status and attributes of the university teacher who represents the model for them in all aspects.

Fourth: according to the variable of student's marks average:

To reveal the significance of differences according to the variable of student's marks average, means, and One-way ANOVA were calculated to see if there were statistically significant differences for the Hashemite University students' opinion about the university professors' features. Table 10 shows these calculations according to the variable of student's marks' average.

Table 10. Means \& SDs \& one-way anova according to student's marks

\begin{tabular}{llllll}
\hline Variable & & No. & mean & f-value & Significance level \\
\hline & Excellent & 63 & 4.03 & & \\
Student's & Very good & 246 & 3.60 & & $* 0.03$ \\
average & Good & 371 & 3.33 & \multirow{2}{*}{1.75} & \\
& Acceptable & 332 & 3.13 & & \\
& Under control & 136 & 2.96 & & \\
\hline
\end{tabular}

* statistically significant at the level of $(\alpha \leq 0.05)$

Table 10 clearly shows the existence of statistically significant differences for the students' opinions according to the variable of students' average. To reveal the positions of these significant differences between the means of the students' opinions according to this variable, researchers used Shefe test for post comparisons so as to discover 
the source of differences, and Table 11 clarifies that.

Table 11. Shefe test for identifying the source of difference according to the variable of student's marks' average

\begin{tabular}{|c|c|c|c|c|c|c|c|}
\hline Variable & & mean & Excellent & Very good & Good & Acceptable & Under control \\
\hline \multirow{5}{*}{$\begin{array}{l}\text { Student's } \\
\text { marks' } \\
\text { average }\end{array}$} & Excellent & 4.03 & & $*$ & $*$ & $*$ & * \\
\hline & Very good & 3.60 & & & * & $*$ & $*$ \\
\hline & Good & 3.33 & & & & & \\
\hline & Acceptable & 3.13 & & & & & \\
\hline & Under control & 2.96 & & & & & \\
\hline
\end{tabular}

As seen in Table 11, there are statistically significant differences for the students' opinions about their professors' characteristics according to the variable of students' marks' average, and for the benefit of excellent and very good students.

This result could be explained that the distinguished students' vision of their professors is unique since they consider them as the source of knowledge who present it gradually so as students could have the reference in all sides. Whenever their dealing with professors increase, students form more positive features about their teachers and they become the model for them.

\section{Recommendations}

Based on the findings resulting from this study, the researchers suggest the following:

1) Considering the university teaching a career that requires pre readiness and preparation.

2) The necessity of informing workers within the teaching domain of the qualities that university professors must have.

3) The necessity of holding periodic meetings between teachers and students so as the benefit is shared in that the professor knows the students' impression about him and the students know the good treatment styles.

4) The necessity of professors' participation in activities held by the university for the students.

5) The necessity of activating the professors' role in academic guiding so as to increase interaction with students.

\section{References}

Abdullah, T. (1997). Some of the University Teacher's Characteristics as realized by Bethlehem University Students. Psychology Journal, 43, 55-75. Palestine.

Awwad, F. A. (2008). The Features of Distinguished Teachers from the Basic Schools' teachers' point of view in the Region of South Amman of UNRWA. Practical Education, Future Visions. The Library of Arab Community for Publishing and Distribution, Amman, Jordan.

Al-Aghbari, A. S. (1996). Features that must be available in the Professor, Recent Education. Modern Education Association, 44, 144-160.

Al-Ghamidi, H. (2003). The professors' Characteristics preferred by teacher's colleges students in KSA. Teachers' Colleges Journal, 3(2), 45-115.

Al-Harahsheh, M., \& Mustafa, A. (2008, April 1-3). The Teacher \& his role requirements in light of recent changes. The First Scientific Conference: The Future of Education in the Arab World in light of the Informational Revolution. Educational Sciences College, Jerash Private University.

Ali, M. (1987). A Comparative Study for Preparing \& Training Professors. The Journal of Arab Universities' Union, 22(79), 32-50.

Al-Khtheileh, H. M. (2000). The Actual \& Ideal Instructional Skills as seen by the King Sau'd University Students. Journal of Um Al-Qura University for Educational, social and humanitarian sciences, 12(2), 107-123.

Al-Naji, M. (1998). The University Professor's Characteistics that are related to supporting students' achievement as seen by professors and students. Within a teaching seminar in the Kingdom of Saudi Arabia: Future Visions, held in Riyadh in the period of 25-28 Shawwal 1418H. 
Al-sahlawi, A. (1992). The Good University Teacher : his qualities \& features from the point of view of some professors and students at the college of education. Educational studies, 8(47), 45-56.

Al-Tartouri, M., \& Jweihan, A. (2006). Comprehensive Quality Management at Higher Education Institutions. Libraries and Information Centres, Ed.1, Dar Al-Maseira/ Amman, Jordan.

Diab, S. (2006). The University Teacher in light of the $21^{\text {st }}$ century challenges (his expected roles, features and basics). The teacher's conference in the $3^{\text {rd }}$ millennium- Isra' Private University, Amman, Jordan.

Frauhold, W. (2003). The knowledge Culture or the knowledge market? About the university's new ideology. Terminal journal for comparative education, 23(1), 32-44.

Haskvitz, A. (2007). Top 11 traits of a good teacher. Retrieved April 17, 2007, from http://www.reacheverychild.com/feature/ traits.html

Hoage, J. (1988, Marth 24). Does Professor's Reputation Affect Course Selection? Paper Presented at the Missouri Valley Economics Association.

Ibrahim, R. R. (2000). The Indicators of Evaluating the University Professor from the College Point of view: Factorial Study. The Egyptian Journal for Psychological Studies, 10(48).

Jacob, N. (2005). The professional competencies \& preferable professor's personal features from the teacher's college of Beisheh (KSA) students' point of view. The Arab Journal for Education. The Arab Organisation For Education. Culture and Science, Tunisia, 25(1), 102-141.

Ja'nini, N. (2000). Basic Competencies for Secondary Stage Teachers in Jordan from their point of view. Dirasat Journal, 57-74. Educational Sciences, University of Jordan.

Kolchak, D. P., \& Eggen, P. D. (1998). Learning and teaching: Research based Methods. Needham Heights, M A: Allyn and Bacom

Mahafzeh, S. (2009). The Future's Teacher: Attributes, skills, competencies. The $2^{\text {nd }}$ scientific conference towards a better investment of the psychological \& educational sciences in light of the generation's challenges, Damascus University.

Ott, M. (1991). Characteristics of New and of Newly Promoted Professional Faculty at the University of Maryland, 8-60. Maryland: The University of Maryland of college Park, 1991.

Roney, K. (2000). Characteristics of effective middle level teachers: A case study of principal, teacher, and student perspectives. Unpublished Doctoral Dissertation. Temple University. Philadelphia, PA.

Woolfolk, A. E. (1998). Teaching for Learning. Needham Heights, MA: Allyn \& Bacon.

\section{Copyrights}

Copyright for this article is retained by the author(s), with first publication rights granted to the journal.

This is an open-access article distributed under the terms and conditions of the Creative Commons Attribution license (http://creativecommons.org/licenses/by/3.0/). 